\title{
A Reply to David Hay's Discussion
}

\author{
Saverio Bozzolan* \\ Department of Business and Management \\ LUISS University \\ Rome, Italy \\ sbozzolan@luiss.it \\ Antti Miihkinen \\ Department of Accounting and Finance \\ Turku School of Economics \\ University of Turku \\ Turku, Finland \\ antti.miihkinen@utu.fi \\ Department of Accounting \\ Aalto University \\ Helsinki, Finland \\ antti.miihkinen@aalto.fi
}

Published 29 April 2021

The comments made by Hay (2021) on our paper raise legitimate questions. While we agree with some of the remarks and will take advantage of the many useful suggestions in our future work, we leave it to the reader to utilize those comments as useful tools to critically analyze our paper.

What we intend to do in the limited space of this reply is to clarify some of the methodological issues underpinning the paper that were the object of attention by Hay. In particular, we would like to discuss three questions that arise in Hay's comments: (1) the accounting standard used, and audit opinion issued; (2) the measurement of risk disclosure quality; and (3) the sample selection and coding process.

*Address for correspondence: Saverio Bozzolan, Department of Business and Management, LUISS University, Rome, Italy. Email: sbozzolan@luiss.it 


\section{The Standard Used and the Audit Opinion Issued}

In his discussion, Hay pointed out that auditors have not usually had a clear benchmark that could have been used in the assurance of client risk reporting. He also stated that the ISA does not provide any guidance on how to audit risk disclosures. In our paper, we contend that during the time window of our study, the auditors followed the Finnish Auditing Act and the ISA standards, which together were the major sources of "good auditing practice," as pointed out in footnote 4 of our paper. We also contend that the Finnish Accounting Act (FAA) and the detailed risk disclosure standard, together, provide a concreted disclosure framework that auditors can use as benchmark and against what the auditors could audit.

Finland has a peculiar history when it comes to the content of audited financial statements. For many years, the Operating and Financial Review (OFR) was one of the reports which belonged to financial statements that companies had to file. This requirement was amended at the end of 2004 when, according to the FAA (law 1304/2004), the OFR was no longer part of the official financial statement, but was still required to be published by firms meeting predetermined criteria, such as public listing status and firm size. At the same time, the FAA was also amended with the requirement to give information on the key risks of the firm in the OFR. This requirement, however, was a very general-level statement consisting of only a couple of sentences, and therefore, it left a lot of room for interpretation. In September 2006, the Finnish Accounting Practice Board (FAPB) published a general guidance for the preparation of the OFRs. This guidance clarifies what highquality risk reporting is. The guidance was detailed and also gave illustrative disclosure examples on risk reporting. The disclosure examples focused on several areas: (1) risk management policy and the organization of risk management, (2) strategic and operations risks, (3) damage risks, and (4) financial risks. The guidance dedicated a significant part to risk reporting, giving many examples and providing a clear benchmark for the auditors on the expected level of risk reporting. As a consequence, the FAA, accompanied by the detailed risk reporting standard, formed a benchmark that auditors could use in their work.

We contend that this setting was especially useful for the analysis of audit firm and partner effect on client risk reporting because both the client firms and auditors were provided with a clear and detailed framework which left little room for speculation on risk reporting and on its quality. At the same time, however, risk reporting was considered "soft accounting information" 
because it was mostly narrative, and therefore, the same content could be provided in different ways (i.e., more or less detail; with numbers or without numbers, etc.). As far as we know, there were no reported cases in which the client or the auditor would have been punished because of incomplete risk disclosures. The question of how much the auditors used the "tick the box" approach as compared to more rigorous analyses of client risk reports against the detailed risk reporting standard was a good starting point for our paper.

To obtain anecdotal evidence on whether the audit partners recognized client risk reporting in their statements, we analyzed 45 audit reports that represent $11.45 \%$ of our sample. We have collected anectodical evidence that the OFR (and thus its content) was an important element of the assurance, and that was also explicitly mentioned in many of the audit reports. An example is this extract from the audit report of Nokia Corporation for the year ending in December 31, 2008, the final year of our analysis (bold added).

Auditor's responsibility

Our responsibility is to perform an audit in accordance with good auditing practice in Finland, and to express an opinion on the parent company's financial statements, on the consolidated financial statements and on the review by the Board of Directors based on our audit. Good auditing practice requires that we comply with ethical requirements and plan and perform the audit to obtain reasonable assurance about whether the financial statements and the review by the Board of Directors are free from material misstatement and whether the members of the Board of Directors of the parent company and the Managing Director have complied with the Limited Liability Companies Act.

An audit involves performing procedures to obtain audit evidence about the amounts and disclosures in the financial statements and the review by the Board of Directors. The procedures selected depend on the auditor's judgment, including the assessment of the risks of material misstatement of the financial statements, whether due to fraud or error. In making those risk assessments, the auditor considers internal control relevant to the entity's preparation and fair presentation of the financial statements in order to design audit procedures that are appropriate in the circumstances. An audit also includes evaluating the appropriateness of accounting policies used and the reasonableness of accounting estimates made by management, as 
well as evaluating the overall presentation of the financial statements and the review by the Board of Directors.

The audit was performed in accordance with good auditing practice in Finland. We believe that the audit evidence we have obtained is sufficient and appropriate to provide a basis for our audit opinion.

All audit reports were clean; that is, no modified opinion was provided. In providing their opinion, auditors state that the financial statements and the OFR give a true and fair view of financial performance and financial position, and that the information in the OFR is consistent with the information in the financial statements. Evidence shows that risk disclosure or specific risks (as specified in the detailed risk reporting standard) were not directly highlighted in audit opinions. Typical references to risks related to the "risks of material misstatement," "risk assessments," and "internal control relevant to the entity's preparation and fair presentation of the financial statements," and these quotes were typically provided in the section which defined the responsibility of the auditor.

We contend that an explanation of the fact the audit reports are clean is that the audit team interacted with management during the preparation of the financial statements, making the management team conscious about what the new regulation prescribes or pushing or encouraging management to set the adequate level of risk disclosure. Company executives do not want to receive a negative audit opinion on the financial statements from the audit firm, and consequently, they were forced through the interaction with the audit firm and with the audit partner to offer the minimal level of risk disclosure requested by the accounting standard, or the additional risk disclosure requested by the audit partner. This explanation is in line with the findings of Miihkinen (2012), who documents the quality impact of the risk disclosure standard.

Based on the qualitative analyses of the subsample of reports, our interpretation is that the auditors have been aware of the new disclosure standard and consider the clients to have fulfilled the required level of risk disclosure, which ensures a true and fair view. We infer that despite the detailed risk reporting environment, the auditors have not considered incomplete risk disclosures a threat for the representation of true and fair view. In this context, the individual differences of audit partners have been the major audit-related drivers for the risk disclosure differences of the clients. 


\section{The Measurement of Risk Disclosure Quality}

The measurement of disclosure quality has been an everlasting challenge in the disclosure literature. We agree with Hay (2021) that our measure ultimately turns out to be based on the quantity of disclosures, but at the same time, we contend that it refers to other dimensions different from quantity that characterize disclosure. We base the structure of our disclosure quality measure on Beretta and Bozzolan (2004) and on the following discussions by Botosan (2004), where she pointed out that disclosure quality should be examined against the regulation because quality is not an absolute construct and it might vary in relation to the user of the information. The Finnish regulation provides a good and understandable standpoint for the analysis of different quality dimensions. Until few years ago, it could have been argued that disclosure quantity represents disclosure quality, but not now. In the era of information overflow, it is no longer clear that more information, as measured by the length of the report, is better. The extent of risk disclosures still plays a role because without a critical mass of information, it is difficult to form an understanding on the issue. However, we argue that disclosure measures other than quantity based that are derived from the regulation (or from the accounting standard) bring more rigor in the assessment of risk disclosure quality.

When we look at the general guidance of the FAPB on the preparation of the OFRs, we can see that it explicitly highlights that risks and opportunities should be described in a balanced way (i.e., balanced treatment) in the OFR to enable the stakeholders to assess the reasonableness of managements' plans from the viewpoint of the risks and opportunities (Section 1.3.2).

Section 2.7 focuses on the evaluation of the most significant risks and uncertainties and other factors that may affect the development of the business. The beginning of the section explicitly highlights that the reporting entity has to assess the most significant risks and uncertainties in a balanced and comprehensive way. This is followed by a categorization of risks into the main topics (strategic risks, operations risks, financial risks, and damage risks). Then, the section underlines that the reporting entity can also utilize its own risk categorization if it better describes the risks involved in the business. The OFR should then define the content of each risk topic and what is meant by that specific risk. The FAPB nevertheless recommends keeping to the risk categorizations that are established for that specific industry. Section 2.7 refers back to the Section 1.3.2 and pinpoints again that 
the future risks and opportunities should be described in a balanced way so that the stakeholders can evaluate the reasonableness of the action plans of the management. This description should also include those tools and other means that the bookkeeping entity utilizes in the management of risks and uncertainties. If these tools and means are not used, that should be also made known. The OFR should focus on the most significant risks as described in Section 1.4.1 that relates to "Relevance," which is one of the preparation principles and underlines that the provided information should be relevant. Those items that are irrelevant do not have to be discussed in great detail. Section 2.7 continues with a more detailed description of examples of the subtopics of strategic, operative, financial, and damage risks. In addition, the standard says that firms following the IFRS have an opportunity to refer to the more detailed information on financial risks as provided in the notes to the financial statements. This section ends with an explicit reference to the avoidance of "boilerplate" disclosure, saying that the examples are not supposed to be applied as such. Every bookkeeping entity should assess the applicability through their own business, taking into account, for example, the industry and the extent of the operations. Finally, the fifth category (risk management) can be derived from the disclosure examples (referred to at the end of Section 2.7), where one section focuses on the risk management policy and the organization of risk management.

We argue that disclosure standard offers a very clear indication about the characteristics that the disclosure should have, and our categorization of the main risk topics and measures for balance and coverage represent how well firms meet the objective provided above. With balance, we measure how evenly the information is scattered across the main risk topics discussed in the standard, and with coverage, we add another layer into the measurement by also considering the number of provided risk topics. We contend that these two dimensions link risk reporting to what the detailed risk reporting standard asks for, and also link the measurement of disclosure more closely to quality. Our measures, however, by being quantity based and standard driven, give a good starting point to compare the quality of risk reporting across and within industries.

\section{Sample Selection and Coding Process}

We would highlight that our sample covers the entire population of the Finnish listed firms, excluding those in the financial sector. Therefore, we did not make any a priori assumptions about sample size. We lost some 
observations due to lack of data and because of listing, delisting, restructuring, or differing fiscal year. However, we have checked if the sample is a representative subsample of the entire population, and we did not find evidence of a systematic bias.

In his discussion, Hay (2021) emphasized some limitations in the coding process. We agree with Hay that manual coding should be conducted with a high level of attention to guarantee robust results. In this regard, we have adopted all the usual battery of tests (i.e., Krippendorf's alpha and coefficient of agreement) to verify that our results are reliable. We obtained reliable coding even though during the study period, we had two different coders involved in the coding process, focusing on different time periods. Obtaining reliable coding with two different coders in two different time periods is indirect evidence of the quality of the coding procedure and the learning activity of the coders.

Moreover, one of the authors coded 26 observations to cross-check the activity of the research assistant. In his discussion, Hay questions whether the sample size is adequate. We agree that this might be an issue, and that one of the most frequent problems in statistical analysis is determining the appropriate sample size. The risk is that if the sample size is too small, it will not yield valid results, while an appropriate sample size can produce accurate results. Moreover, the results from a small sample size will be questionable. Regarding sample size, there is no certain rule of thumb to follow. In regression analysis, a widespread rule of thumb is that there should be at least 10 observations per variable, so if there are two independent variables, then a rule would be to have a minimum sample size of 20 observations. In our case, we have a sample size of 26 observations used to cross-check risk disclosures over a population of 393 firm-year observations. Although it is documented in Miihkinen (2012) that on average, firms improved their risk disclosure after the introduction of the detailed standard, we would point out here that disclosure behavior tends to be comparatively sticky in the sample years following the detailed guidance. Our analysis shows that firms are relatively consistent over time in the disclosure of risks. Based on this consideration, we have cross-checked the disclosure of 26 different firms over a population of 111 unique firms - about $25 \%$ of the firms analyzed in our paper. 


\section{Summary and Conclusions}

Following what Hay (2021) has pointed out in his high-quality discussion, we have tried to address the most relevant issues by discussing the disclosure standards affecting auditors' work, providing anecdotal evidence on audit reports from the perspective of risk disclosure and the assurance of the OFRs, and by discussing both the rationale and the reliability of our measurement of disclosure quality.

In his discussion, Hay has perfectly identified our intended contribution to the literature, and we here conclude our reply with some thoughts on the potential further development of the paper. One further development of the paper goes toward the investigation of the regime that might be needed to ensure that a high number of firms provide high-quality assurance of nonfinancial information. Another development that should be mentioned is the value of the assurance of risk disclosure and, more generally, of "soft" narrative information. Because only some firms and some auditors are capable of providing positive value with assurance, it can be interpreted that the assurance of non-financial information is still a developing area and could be studied by understanding the drivers of the assurance of softer accounting information more in detail.

\section{References}

Beretta, S., \& Bozzolan, S. (2004). A framework for the analysis of firm risk communication. The International Journal of Accounting, 39(3), 265-288.

Botosan, C. A. (2004). Discussion of a framework for the analysis of firm risk communication. The International Journal of Accounting, 39(3), 289-295.

Hay, D. (2021). Discussion of "The quality of mandatory nonfinancial risk disclosures and the moderating effect of audit firm and partner characteristics." The International Journal of Accounting, 56(2).

Miihkinen, A. (2012). What drives quality of firm risk disclosure? The impact of a national disclosure standard and reporting incentives under IFRS. The International Journal of Accounting, 47(4), 437-468. 